\section{REALIDAD Y ACTUALIDAD. UNA PRIMERA APROXIMACIÓN AL TEMA DEL CUERPO*}

\author{
Ricardo Espinoza Lolas ${ }^{1}$ \\ Pontificia Universidad Católica de Valparaíso \\ respinoz@ucv.cl \\ Paula Ascorra Costa ${ }^{2}$ \\ Pontificia Universidad Católica de Valparaíso \\ pascorra@ucv.cl \\ Esteban Vargas Abarzúa ${ }^{3}$ \\ Pontificia Universidad Católica de Valparaíso \\ esteban.vargas@ucv.cl
}

\section{REALITY AND TOPICALITY. A FIRST APPROACH TO THE SUBJECT OF THE BODY} * Este artículo es parte del Proyecto Fondecyt N 1110507: “Realidad y cuerpo en Zubiri”. Investigador Responsable: Dr. Ricardo Espinoza
Lolas. Alumnos tesistas: Mg. Eugenia Colomer Espinoza (E-mail: eugenia.colomer@ucv.cl) y Ronald Durán (ronaldbeat@gmail.com).

Cómo citar este artículo/ Citation: Espinoza Lolas, R.; Ascorra Costa, P. y Vargas Abarzúa, E. (2013). Realidad y actualidad. Una primera aproximación al tema del cuerpo. Arbor, 189(760):a017. doi: http://dx.doi.org/10.3989/arbor.2013.760n2003

Recibido: 14 agosto 2012; Aceptado: 18 enero 2013.

RESUMEN: El presente artículo indaga en el pensamiento del último Zubiri, esto es, Ilamado noología, y desde la trilogía de la inteligencia: Inteligencia sentiente (1980-1983) y del escrito El concepto de materia, la articulación entre realidad y actualidad como soporte conceptual para comprender una filosofía del cuerpo humano que integre, por una parte, la filosofía zubiriana a lo largo de su obra y, por otra parte, que nos posibilite entender al hombre en su radical unidad corporal constitutiva tanto en el cosmos como en el mundo.

PALABRAS CLAVE: Zubiri; realidad; ser; actualidad; presencia; cuerpo.
Copyright: (C) 2013 CSIC. Este es un artículo de acceso abierto distribuido bajo los términos de la licencia Creative Commons Attribution-Non Commercial (by-nc) Spain 3.0.

ABSTRACT: This article explores the later thought of Zubiri, i.e. so-called noology, from viewpoint of the trilogy of intelligence: sentient intelligence (1980-1983) and writing on the concept of matter, the links between reality and actuality as the conceptual underpinning for an understanding of a philosophy of the human body that integrates both the philosophy of Zubiri over the course of his work and also enables us to understand man in his radical constituent bodily unity in the cosmos and the world.

KEYWORDS: Zubiri; reality; being; news; presence; body. 


\begin{abstract}
"La actualidad de lo inteligido y de la intelección es numéricamente la misma", Xavier Zubiri, Inteligencia y realidad...
“... en cuanto personal, este mismo cuerpo transciende de toda integración: el cuerpo es personal pero lo es formal y precisamente no como organismo ni como sistema solidario, sino como principio de actualidad", Xavier Zubiri, Inteligencia y realidad...
\end{abstract}

\section{INTRODUCCIÓN}

Para entender las sentencias que dan inicio a este artículo y que nos permitirán profundizar en una primera instancia lo que sería el cuerpo en el último Zubiri, recordemos la primera de ellas: "La actualidad de lo inteligido y de la intelección es numéricamente la misma" (Zubiri, 1984, 156). Tenemos que pensar propiamente lo que es la actualidad y en ello de inmediato se hace patente el problema de la articulación entre realidad y ser. Pero ¿qué es la "actualidad"1? He ahí la pregunta fundamental. Actualidad es el: “... estar presente desde sí mismo por ser real" (Zubiri, $1984,139)$. ¿Qué mienta ese "estar presente"? Vayamos por pasos contados; ahora nos sumergiremos, para comenzar, en tales palabras para que, de este modo, podamos sacar a la luz lo que verdaderamente se esconde tras ellas. Para esto, estaremos totalmente abocados a las determinaciones de la actualidad en la obra final (Inteligencia sentiente) de Zubiri pues solamente desde allí entenderemos, más adelante, el cuerpo como un modo de ser actual "aquí", pero también pensaremos la actualidad desde lo publicado en el escrito El concepto de materia ${ }^{2}$. Desde estos textos analizaremos, de modo somero, el concepto de actualidad y lo haremos así porque, aunque a lo largo de su extensa obra filosófica Zubiri siempre haga hincapié en el término "actualidad", su sentido se va perfilando hacia el final de su vida y es en estos textos donde se dan fundamentales matices nuevos. El concepto ha sido utilizado de distintos modos; incluso se utiliza, en obras del comienzo de su vida filosófica, el término en forma completamente distinta a lo que piensa luego en su obra sobre la intelección (en el sentido de acto como plenitud, esto es, lo que llama como "actuidad"). Además, como nuestro rumbo es fijar la realidad como formalidad de actualidad y desde allí entender el cuerpo, en un primer momento, nos detendremos en la actualidad qua actualidad "allende" cualquier aprehensión y como momento de lo real, esto es, el "principio de actualidad" como fundamento. Aunque esto es investigar la metafísica zubiriana, lo cual escapa a nuestro propósito explícito en este artículo, tenemos que hacernos cargo de ello, porque el problema del ser nos lleva a pensar desde lo que se impone en la aprehensión primordial hasta lo que se construye por la razón; y en ambos dominios, la actualidad tiene mucho que decir. Y es en la articulación realidad y ser donde el cuerpo, la materialidad, cobra sentido como principio de actualidad de todo lo real y, en especial, del hombre. Pero esto ya lo veremos más adelante.

\section{REALIDAD Y SER. ACTUIDAD Y “ACTUIDAD”}

Tratemos entonces de comprender qué significa que actualidad sea un "estar presente de lo real desde sí mismo en cuanto real" y en ello veremos cómo la actualidad se entiende desde la actuidad (el carácter de plenitud de la realidad); es el viejo problema zubiriano de la articulación entre realidad y $\operatorname{ser}^{3}$. Para entrar en este problema empecemos por indicar lo que no es la actualidad. Y para esto se contrapone la diferencia esencial de este término con el de acto, que Zubiri llamará "actuidad", que fue expresado, en cierto sentido, por los griegos y que es uno de los pilares de la metafísica occidental. Así, Zubiri nos dice:

\begin{abstract}
"El vocablo y lo conceptuado en él ocultan un equívoco que es menester denunciar muy expresamente. Lo que tradicionalmente se ha llamado actualidad (actualitas decían los medievales) es el carácter de lo real como acto. $Y$ entendieron por acto lo que Aristóteles Ilamo enérgeia; esto es, plenitud de la realidad de algo. Así, decir que algo es perro en acto significa que este algo es la plenitud de aquello en que consiste ser perro... A todo lo real por tener plenitud de aquello en que su realidad consiste $y$, por consiguiente, por poder actuar, es a lo que se llamó ser real en acto. A este carácter de lo real es a lo que se llamó actualidad. Pero esto es ante todo una denominación impropia. A este carácter debe llamarse más bien actuidad. Actuidad es el carácter de acto de una cosa real" $(1984,137)$.
\end{abstract}

Esta determinación, en contraste didáctica, de la actualidad con relación a la "actuidad" es muy tardía en el pensamiento de Zubiri. Él mismo no lo hacía en sus escritos anteriores, por ejemplo, en Naturaleza, Historia, Dios (1944) y se puede ver aquí que cuando habla de actualidad, en numerosos pasajes, se está refiriendo a la enérgeia de Aristóteles. He aquí, un ejemplo de lo dicho, en donde se ve claramente que actualidad es entendida como enérgeia:

"Las cosas reales tienen, en cierto modo, palpitante actualidad ante la mente. Sin embargo, las cosas no son su actualidad ante la mente. Precisamente, las cosas actuales tienen actualidad porque previamente son actuales. Y a esta otra actualidad previa es a lo que el griego llamó realidad: una especie de operación en que algo se afirma sustantivamente. Aristóteles lo llamó enérgeia" (Zubiri, 2004, 81). 
Tampoco en su gran obra metafísica Sobre la esencia (1962) tiene este término gran importancia. El término parece ser usado en general para explicar a Aristóteles y en ello para la distinción de acto como actividad y actualidad ${ }^{4}$. Solamente desde La dimensión histórica del ser humano (1974 y publicado en 2006 en Tres dimensiones del ser humano) el término va ganando en relevancia y autonomía, para luego ser, en su etapa noológica, un término fundamental y central (termino que se vuelve cómo el horizonte desde dónde se da toda la noología). No solamente es fundamental el término en esta obra final de Zubiri, sino que recubre la obra entera de nuestro pensador de modo retrospectivo. Por lo tanto, hay que tener mucho cuidado a la hora de interpretar este nuevo concepto a lo largo de su obra filosófica. "Actuidad" como abstracto de "acto" mienta simplemente el carácter mismo de lo real en plenitud. No debemos creer que nuestro pensador niega este carácter o lo considera de modo peyorativo al hablarnos de la actualidad. Nada hay más alejado del pensamiento zubiriano. Lo que sucede es que en vez de utilizar este término de "actuidad", Zubiri emplea simplemente "realidad". Así de fuerte es la comprensión de la "actuidad". En vez de ser negada la "actuidad", ésta queda totalmente asumida en la concepción misma de la realidad, pero como "formalidad de realidad" (en esto Zubiri se aleja del realismo de Aristóteles y adquiere su filosofía una "plasticidad" única). Por esto, a veces, las emplea como sinónimos: "Actualidad y actuidad no son idénticos, pero esto no significa que sean independientes... la aprehensión... es siempre y sólo actualidad de lo que es «en propio»; esto es, actualidad de la realidad, de la actuidad. Por tanto, toda actualidad es siempre y sólo actualidad de lo real, actualidad de actuidad" (Zubiri, 1984, 140).

En este texto, se equiparan a "actuidad" los términos "en propio" y realidad. Si la actualidad es actualidad de "actuidad" podemos ver que es la "actuidad" misma, esto es, la realidad "de suyo" la que por ser física da de sí lo físico de la actualidad y aquí ya debemos ir viendo el carácter material de la realidad: "De ahí que la actualidad, a pesar de ser un carácter distinto de la "actuidad», es, sin embargo, un carácter a su modo físico" (Zubiri, 1984, 140). Esto es muy importante hacerlo notar porque de inmediato nos damos cuenta de que en la actualidad estamos sumidos en el ámbito de la impresión (en lo material) y no en algo que esté por fuera de lo físico, es decir, del carácter impresivo de lo aprehendido (Zubiri fue siempre muy crítico con la Fenomenología por la eliminación del carácter físico en la aprehensión por su célebre "epoché" $)^{5}$ y esto es totalmente importante para dar con una concepción del cuerpo en la noología zubiriana final. En el cuerpo nos encontramos propiamente con la actualidad en tanto física de lo real humano. Por esto Zubiri es tan tajante al decirnos: "La intelección como acto no es formalmente intencional. Es un físico "estar»" (Zubiri, 1984, 23).

"Actualidad" es el abstracto del carácter de "actual", no del carácter de acto ("actuidad"). Pero la intrínseca ligazón entre ambos términos nos queda mejor comprendida por el rasgo físico de la realidad: "Actualidad es un momento físico de lo real, pero no es momento en el sentido de una nota física suya. El momento de acto de una nota física es actuidad. Su otro momento es también físico, pero es actualidad" (Zubiri, 1984, 138). Es decir, todo consiste en saber qué es lo físico de la actualidad. Sin embargo, ya sabemos que es lo que corresponde a lo físico de la "actuidad" que, en definitiva, es lo físico mismo de la realidad. Lo físico de la "actuidad" está en el ámbito de la nota propiamente tal de lo real que se impone al aprehensor. Esto es, el contenido mismo, al ser sentido, se nos impone como real en la aprehensión primordial y, por tanto, nos deja sumidos en lo físico mismo de sí6; un carácter físico que siempre se abre a más realidad; es el "más" sentido que excede tal imposición real y que da de sí la actualidad misma.

\section{LOS MODOS DE LA ACTUALIDAD}

¿En qué consiste, entonces, lo físico de la actualidad? Tal respuesta permitirá indagar noológicamente en una posible concepción del cuerpo. Zubiri responde esta pregunta en distintos niveles; nosotros seguiremos el propuesto en Inteligencia y realidad, pero complementado con textos de El concepto de materia; y esto debido a que son textos de la misma época de gestación y porque en este libro (El concepto de materia) está en su contexto íntegro lo que se ha sintetizado en aquél (Inteligencia y realidad).

Para responder a esta pregunta, hay que considerar que lo real puede ser visto desde un triple modo de consideración. En este triple modo está vehiculada la actualidad como momento físico de lo real (de la "actuidad") en presentación. La actualidad puede ser un "tener actualidad", un "hacerse actual" y un "estar actualmente" (sin, embargo, aquí radicaría lo propiamente corporal en sentido noológico). Los veremos a continuación por pasos contados.

\subsection{Tener actualidad}

El momento de "tener actualidad" es un momento extrínseco de consideración de la actualidad. Y nos indica la "mera" actualidad de una cosa que se presenta en medio de otras, ya sea para alguien ya sea para una sociedad ya para la historia. Zubiri nos da el ejemplo del virus para comprender este sentido extrínseco, pero totalmente verdadero de la actualidad: 
"La actualidad puede ser una actualidad meramente extrínseca a lo real, a lo actual. Consiste entonces en que algo tenga actualidad "para» alguien, para una sociedad, para un momento histórico determinado, etc. Entonces decimos que las cosas reales en cuestión pueden tener o no tener actualidad, tener poca o mucha actualidad, etc. Es la actualidad como presencialidad extrínseca a lo real. Esta presencialidad, en efecto, no afecta a lo real. Así, los virus tienen hoy gran actualidad para nosotros. Pero a quien afecta esta actualidad no es a los virus sino a nosotros. Por esto, esta actualidad es extrínseca a la realidad viral. En este sentido decimos que lo real "tiene» (o no tiene) actualidad" $(2008,365)$

Con este modo extrínseco de consideración, la actualidad solamente es tomada de modo inesencial respecto de lo real, esto es, lo real no queda en y por sí mismo en el carácter de actualidad, sino que es una consideración que reposa por fuera de lo real mismo, reposa en quien denota la "presencia" de tal o cual realidad, en este ejemplo, el virus "para" la sociedad de este siglo. En el dominio de la actualidad como mero "tener" actualidad, ésta es algo que lo real puede o no tener, pues reposa en un modo de consideración de lo real quoad nos. En este modo extrínseco de entender la actualidad, el filósofo ve, una vez más, la diferencia entre "actuidad" y actualidad. Pues la "actuidad" sería la realidad vírica que en plenitud de lo que es, por sus notas que la constituyen en y por sí misma, queda completamente al margen de una consideración quoad nos del modo de presentarse que ésta tiene en lo puntual de un aquí y un ahora. Por esto se señala que:

“... al decir que los virus son algo que tiene mucha actualidad, decimos que son algo que está hoy muy presente a todos. Aquí se percibe ya la diferencia esencial entre actuidad y actualidad. Los virus son siempre realidades en acto. Sin embargo, su estar presente a todos no es actuidad. Hace muchos años los virus carecían de esta presencia: no tenían actualidad" (Zubiri, 1984, 138).

En esto consiste el "mero tener actualidad" de lo real, esto es, la "pura" presencialidad de lo real de la mera relación extrínseca, sin embargo, es esa "pura" presencialidad donde se constituye externamente lo real y su cuerpo; es como un mero estar a la luz de unos con otros, en lo externo de un notificarse.

\subsection{Hacerse actual}

Pero la actualidad tiene un modo más esencial de ser considerada, es el "hacerse actual". En el "hacerse actual" la actualidad cobra un sentido intrínseco, porque lo real "desde sí mismo" se "hace" presente. Lo extrínseco de una visión que relaciona lo real con respecto de alguien o de otras cosas cede a favor de una concepción en que la cosa: "desde sí misma" se haga presente, se impone. Zubiri nos muestra el ejemplo de las personas para que podamos captar en toda su magnitud este tipo de actualidad:

“... actualidad puede tener otro sentido, que no deroga al anterior, pero que es mucho más radical que él: es algo no extrínseco sino intrínseco a lo real. ¿Qué es esta actualidad? Esta actualidad es, por ejemplo, lo que tratándose de personas expresamos diciendo que tal persona "se hace presente». En este caso, actualidad no es la actualidad que esa persona "tiene» para los demás o para las demás cosas, sino que es un momento real de la persona misma; es algo que concierne a ella y no sólo a los demás. Es ella misma la que se hace presente por sí misma, en un "hacer» que concierne a su realidad propia. Este «hacer» por sí mismo es justo la actualidad de esa persona. Es una actualidad que es intrínseca a la realidad de esa persona, es un momento intrínseco de su realidad" $(2008,365)$.

Este texto es muy interesante pues este nuevo tipo de actualidad, no deroga la anterior, sino en cierta forma la recubre y la eleva de modo esencial (esto es un estilo muy hegeliano). Se nos indica el ejemplo de la persona. Cuando nos movemos como este pensador en el decir de su modo descriptivo ("constructo" diría él $\left.{ }^{7}\right)$, es muy importante que lo que se describa sea un dato que se nos impone y no una teoría (aunque ésta sea muy plausible y no se discuta). De allí que el ejemplo de la persona, y esto es interesante señalarlo, debe entenderse como algo dado en aprehensión. La persona es algo real que se nos impone (ése es su carácter físico) en nuestra vida cotidiana de modo radical y es porque somos nosotros mismos quienes nos actualizamos de ese modo, primeramente ante sí mismo (de modo impresivo) y luego ante los otros. Y ante el peso de este ejemplo, no cabe el modo solamente extrínseco de actualidad, esto es, el extrínseco de mera presencialidad sino que ante todo, el mero presente reposa y se funda en la actualidad como " $h a-$ cerse presente"; aquí se da un cierto carácter accional de lo real. Es la persona que desde sí misma y por sí misma se "hace" presente, se notifica, se signa ${ }^{8}$ ante las otras cosas reales (cosmos) y ante "la" mera realidad (mundo) de las cosas reales; en esto, ya se puede ver el cuerpo en su aparición fenoménica propiamente tal; es la actualidad que en su hacerse actual debe somatizarse. Este "hacer" no está demandado por las cosas reales, sino que se funda en el mero carácter afirmativo de realidad que lo constituye; éste es el carácter "de suyo" de la realidad en tanto que "prius". Aquí, creemos, es donde se funda la posibilidad de cualquier filosofía "ética" del otro en tanto que Otro (por ejemplo, la filosofía de Levinas). Es donde el hombre, por ser hombre, se "hace necesariamente actual" como tal hombre; en la inespecificidad de cualquier contenido preciso, el hombre "es"; "es" hombre en el mundo simplemente por ser hombre (aquí podemos 
ver filosofías que van desde Kant a Derrida pasando por Kierkegaard, Levinas, etc.). Es la plenitud del acto mismo de ser real la que se "hace" presente; por tanto, esta actualidad reposa en la "actuidad" de lo real: "Este hacer no es un hacer algo consigo mismo o con las cosas, sino que es un hacer que lo único que hace es la mera presencialidad de lo que ya es, es el mero presente de la persona. Por esto no es actuidad de la persona sino actualidad suya" (Zubiri, 2008, 365). Aunque este tipo de actualidad es intrínseca y constitutiva del tipo anterior de actualidad no por eso es del todo esencial, pues ella está, por así decirlo, en el plano del contenido de lo real. Esta actualidad está dada en y por el contenido (nota) de lo real, por ejemplo, ser hombre, pero no por ser tal hombre determinado, pero si hombre al fin y al cabo. El hombre como una forma y modo de ser real, pero no por ser tal o cual hombre biográfico (empírico diría Hegel). Luego, se necesita una actualidad que sea en y por sí misma del carácter de realidad de lo real. No basta con que lo real en y por sí mismo esté presente en la aprehensión, se requiere ante todo que lo real en y por sí mismo esté presente ya, como un "prius", desde el mero carácter de realidad y no por el hecho de las notas que lo constituyen. Esto nos lleva inexorablemente al tema de la actualidad en su tercer tipo, que resulta ser el modo esencial y fundante de las otras actualidades. Y esto es, creemos, lo buscado por Zubiri durante años, lo propiamente corporal en sentido noológico. Esta actualidad es el "estar actual", la cual es fundamento del "hacerse actual" y posibilita el "tener actualidad". Esta actualidad es la actualidad del mero carácter de ser real, independiente del contenido que sea, por ejemplo, hombre, animal u otra forma de realidad. El "estar actual" es lo que estudiaremos a continuación, pues, allí radica, creemos, que el cuerpo sea la actualidad como principio de lo real humano en el cosmos abierto mundanalmente ${ }^{9}$.

\subsection{Estar actual}

Lo que sucede es que todo se juega en el "estar" de la actualidad. Para que podamos entender de modo adecuado el tercer momento de la actualidad, el momento radical para dar con la realidad, es necesario que someramente nos quedemos detenidos todavía en el segundo momento de la actualidad y nos centremos brevemente en el "estar" desde sí mismo de lo real que se presenta (que es): “... la actualidad es un carácter del "estar». Ahora bien, "estar» es el carácter mismo de lo real" (Zubiri, 2004, 81). Este "estar" es fundamental en la filosofía última de Zubiri, el verbo que mienta la realidad en sentido pleno y activo; y es el fundamento del ser. Se ha dicho, a veces, que realidad es un "reificar", esto debe entenderse, de modo más adecuado, desde el verbo "estar"; esto es, "reificar" es formalmente "estar". ¿Por qué debemos entender la actualidad desde el "estar"? El vocablo de actualidad y en ello el de "estar" es fundamental en el último Zubiri y esto lo aleja de las filosofías de ser, en especial, del primer Heidegger (Sein und Zeit de 1927). Por ejemplo, para comprender el problema de la articulación entre realidad y ser nuestro filósofo nos señala magistralmente el concepto de "estar" como la articulación constructa misma de ambos momentos, pero un estudio detallado de esto nos llevaría muy lejos de nuestra pretensión. Pues implicaría hacernos cargo del problema del ser en el pensamiento zubiriano y cómo éste se articula con la realidad. Sin embargo, aquí nos detendremos en el "estar" de lo real, pero en su carácter de ser aprehendido como tal y someramente hablaremos del ser. Y si podemos comprenderlo de modo claro, podremos ver que la concepción noológica del cuerpo no es una concepción de tinte fenomenológica en donde el cuerpo es un carácter solamente de presencia o de soma, como lo era el Zubiri de los años treinta, sino que es un cuerpo físico que "está" presente; que por ser físicamente está siendo en fuerza impositiva y de arrastre (al igual que Nietzsche, Zubiri tiene una concepción de la Naturaleza de forma activa); de allí que el carácter de soma, de cierta luz, de cierta presencia en la línea del ser, abierta por la ontología heideggeriana, se quedaba corta ${ }^{10}$.

La actualidad como un "estar actual" nos señala que lo real está desde sí mismo, pero no solamente por su modo de contenido presente, sino que eminentemente lo está por su carácter físico de realidad, por ser simplemente físico. De lo dicho no debemos caer en dos equívocos que se pueden deslizar en la interpretación de la actualidad. El primero consiste en creer que actualidad es solamente el "estar" del "estar presente"; esto conllevaría una escisión en la concepción misma de la realidad (que a veces se da en sus interpretes) y sería un error gravísimo. Nuestro pensador pretende dar unidad al problema de la realidad y ser con su concepción de la actualidad como un "estar presente"; desgajar esta unidad es producir e introducir un dualismo donde no lo hay. Esto es muy importante, creemos, para una concepción del cuerpo noológico que no pretende caer en la escisión de entender el cuerpo como mera superficie somática de inscripción fenoménica en contra del carácter propiamente tal del cuerpo que funciona como anterior a toda superficie; como un "prius" último, posibilitante e impelente de la superficie somática. Pero esto no quiere decir que en la actualidad misma no se produzca un cierto constructo en donde dos o más notas tienen distintos modos de dominancia entre sí; una dominancia que siempre opera como "prius" de un momento en los otros. El "estar" domina y constituye el presentarse (muy similar al constructo DionisosApolo de Nietzsche), al ser como presencia ${ }^{11}$, y esto es claro y es el avance filosófico final de Zubiri res- 
pecto de sí mismo a lo largo de los años en torno al problema del cuerpo (y con ello de la naturaleza, la materia y de Dios mismo) ${ }^{12}$. El segundo equívoco radica en creer que solamente la actualidad sería "que lo real desde sí mismo está presente", pero lo "está" por su momento de nota (contenido). Lo que sucede es que no es la nota o contenido de lo real lo esencial de la actualidad. Y no podría serlo porque la nota es tal desde la física realidad que lo constituye como tal: “... la cosa real puede estar presente o no estarlo según sean sus notas. Pero lo que sí es inexorable es que todo lo real en su formalidad de realidad (y no sólo por sus notas) está presente desde sí mismo. Este es un constitutivo carácter de todo lo real" (Zubiri, 1984, 139). Y así el tercer tipo de actualidad se nos muestra como el sentido pleno de ella. La actualidad como un "estar actual" es el fundamento mismo del "hacerse actual" de lo real desde sí mismo por su momento de contenido, y es este momento, a su vez, el que posibilita, como un "más" que excede, la actualidad extrínseca relacional del "tener actualidad". El tercer tipo de actualidad es la esencia misma de ella: “... estar presente desde sí mismo por ser real: he aquí la esencia de la actualidad" (Zubiri, 1984, 139). No es lo mismo que alguien "tenga actualidad" porque es muy "famoso", por tener "dinero", por ser presidente de un país, padre de alguien, mártir, Juan Pérez, etc., que por ser hombre, que "acontezca actualmente" por ser hombre, por "hacerse actualmente hombre"; hombre sin más, meramente hombre. $Y$ no es lo mismo esto que ser real, que estar siendo actualmente real. Ese carácter de acontecimiento físico de imposición presentante ("prius") del carácter real del hombre sería la base de un cuerpo noológico que trasciende en tanto "más" tal cuerpo y se vuelve social e histórico en un dinamismo cinestésico que siempre da de sí en "hacia" a más profundización corporal y así se va corporizando la realidad. Es un paso de profundidad mayor en el análisis que Zubiri solamente deja bosquejado al final de su vida.

Veamos este tercer tipo de actualidad en la exposición de El concepto de materia. Desde este texto cobra una dimensión muy fuerte el carácter esencial de la actualidad por el modo en que se expresa. Los ejemplos iluminarán nuestra explicación y nos llevarán por buen camino, por el camino de la realidad como formalidad de actualidad en la línea de una posible noología del cuerpo:

"La actualidad... no es algo que se "tiene» o algo que se "hace» sino algo que se "es» [en que se está]. La actualidad no es algo extrínseco a lo real sino algo intrínseco a lo real, pero no es en lo real un modo intrínseco adquirido (como en el «hacerse actual»), sino un modo intrínseco a su propia realidad en cuanto realidad. Es lo real que en cuanto real está presente a todo lo real, no por un «hacerse», sino por ser real. No es un hacerse presente por sí mismo, sino un estar presente desde sí mismo por el mero hecho de ser real. No es, repito, un "tener» ni un "hacer» sino un "estar»" (Zubiri, 2008, 366).

Este texto es uno de los más logrados de Zubiri para dar cuenta de modo sumamente clarificador del tema de la actualidad esencialmente tratada y nos da señales para entender el cuerpo en su noología del físico "estar" real. Y es el "estar" la clave de su comprensión. No olvidemos que lo que buscamos es dar con la unidad misma de la realidad como formalidad; y esa unidad poco a poco se va mostrando en este texto a través de ciertos momentos de la realidad como actualidad; momentos como "de suyo", "prius", "más" y "hacia" van dando de sí los rasgos para entender la actualidad; para así dar de modo incipiente, en este artículo, con una concepción del cuerpo físico noológico. Bueno, esa unidad del "prius", "más" y "hacia” es propiamente la actualidad, pero entendida desde el "estar"13, esto es, en lo que consiste el carácter físico de la realidad de lo real aprehendida en aprehensión primordial; aprehensión que, en primera instancia, es de la propia realidad humana como cuerpo noológico.

Esta actualidad física del estar, que se expresa en estas categorías noológicas ("prius", "más" y "hacia”), es lo que mienta a modo de una ontología el concepto de "presencia", esto es, el ser. El ser es la expresión ontológica de la actualidad de la física realidad. En el ámbito de la actualidad queda bastante notorio que el modo de presencia del "ser" es cobrado y ulterior al carácter de "estar"; el "presentarse" es cobrado y fundado en y por el "estar" del "estar presente" y en esto consiste formalmente la actualidad (y no olvidemos que no hay nada detrás del "estar"). La presencia: "... es una simple pero inexorable consecuencia de la actualidad como "estar actualmente»" (Zubiri, 2008, 366). ¿Cómo entender ese estar actualmente? Tales términos parecen ser un mero juego de palabras, pues si actual significa "estar presente" entonces la expresión "estar actualmente" significaría "estar-estar presente"14. Y ¿ ¿cómo se podría entender semejante expresión? Para tratar de entender esta sentencia veamos lo que dice nuestro pensador a través de un ejemplo. Zubiri analiza en El concepto de materia distintos modos de "estar actualmente", esto es, simplemente modos de "estar" de lo real en el cosmos y esto es algo que el pensador no realiza en otros textos. Su estudio es breve, pero brillante; sin embargo, no podemos entrar en esta cuestión, pues nos llevaría lejos de nuestro estudio de la concepción de realidad como actualidad como fundamento del cuerpo desde la mirada noológica. Pero, a modo de ejemplo, Zubiri da uno muy bello que muestra perfectamente el "estar actual" de lo real:

"En el caso de la realidad humana, hay fenómenos que no son caracteres de los procesos estructurales 
de su realidad psico-orgánica. Por ejemplo, la mera presencia de un hombre a otro no es función de su actuación. Aunque para ello actúa y tenga que actuar, la presencia de un hombre a otro no consiste en esta actuación, sino que es un modo de «estar actualmente». El hombre, además de sus vicisitudes psico-orgánicas normales y patológicas, tiene fenómenos como la "expresión», a la cual pertenece como momento esencial la "fisonomía». Expresión y fisonomía no son procesos de actuación. Evidentemente, los procesos determinan la expresión y la fisonomía, pero no las constituyen formalmente. Expresión y fisonomía son simplemente cualidades de la actualidad en que está todo hombre por el mero hecho de ser real. La fisonomía en cuanto tal es una cualidad de la actualidad de la sustantividad humana psico-orgánica, es una actualidad del «estar actualmente»" (2008, 366-367).

La fisonomía y la expresión del hombre como cualidades de actualidad es un "estar actualmente" del hombre en el cosmos. En este ejemplo, podremos vislumbrar cómo Zubiri, al final de su vida, por fin ya está bastantemente claro en su filosofía para dar con una concepción madura del cuerpo a la luz de lo mejor de su noología de la actualidad. El hombre "está" en el mundo transcendentalmente (Heidegger trabajó esto en detalle en Sein und Zeit de 1927, y fue su tema durante toda la vida), pero talitativamente "está" en el cosmos y "está" en una cualidad determinada de actualidad (replegada diría Deleuze); aquí radica el cuerpo (los cuerpos son pliegues de realidad). En este cruce entre lo trascendental y lo talitativo acontece físicamente el cuerpo y se nos impone como tal. Lo real "está" en medio de cosas reales (cosmos), pero queda en "Ia" realidad de ellas (mundo). Entonces, hay una doble consideración de la actualidad. Por una parte, la talitativa o cósmica en que lo real está como un "estar aquí" y no en abstracto ni en cualquier parte, sino "aquí"; el cuerpo es fundamental en esta dimensión para entender la actualidad en su realización efectiva y en ello lo somático embellece, estructura, da unidad, organiza y diferencia al cosmos entero desde el hombre. El cuerpo, en una primera afirmación noológica, es el "estar aquí" radical de lo real humano en la realidad, por ser real en tanto fuerza impositiva y de arrastre:

"Por el hecho de ser talitativamente respectivo, lo real no sólo es cósmicamente respectivo "a» otras realidades cósmicas, sino que está presente «en» el cosmos. El «en» no es ahora el mundo sino el cosmos. El «aquí» es entonces estar presente «en» la realidad cósmica... actualidad es un estar "aquí», es un estar «en» el cosmos" (Zubiri, 2008, 371).

$\mathrm{Y}$, por otra parte, una actualidad transcendental mundanal en que lo real queda como "ente". El ser es esa actualidad mundanal ${ }^{15}$ gracias a lo cual lo real se vuelve "ente" y en el caso humano subjetividad social e histórica (yo $)^{16}$. Pero esto es posible porque lo real no es formalmente "ente" de ninguna manera sino simplemente lo "de suyo que es" ("está" siendo) en el mundo y en el caso humano real es simplemente cuerpo real antes que yo (y en esto concuerdan Nietzsche y Zubiri claramente: el cuerpo es anterior al yo) ${ }^{17}$ :

“... lo real no es ente, sino que es lo de "suyo» en cuanto tal. Sólo siendo real tiene lo real una ulterior actualidad en el mundo. Esta actualidad es el ser, y lo real en esta actualidad es el ente. Realidad no es ente; la realidad tiene "de suyo" su entidad, pero la tiene tan sólo ulteriormente. Realidad no es formalmente entidad" (Zubiri, 1984, 226).

Este pasaje es un tanto sorprendente porque nos hace evitar el equívoco de creer que Zubiri elimina por completo la noción de "ente" de su vocabulario filosófico. Pero esto no es así en absoluto. La antigua categoría de "ente" (tan importante para la Escolástica o para Heidegger) sigue presente en este pensamiento sobre la formalidad de realidad, pero ocupa su justo lugar, su apropiado lugar. Todo lo real tiene ese momento de "ente" y todo hombre tiene ese momento de yo, es el momento por el cual lo real se actualiza en el mundo; es decir, es lo real "siendo" en el mundo. Dicho con mayor rigor, es lo real en cuanto "está presentándose" en el mundo, pero se presenta desde un "aquí" corporalmente que siempre es anterior, "prius", al modo de ser yo del hombre.

\section{EL DEVENIR FÍSICO DE LA “ACTUALIDAD”}

La actualidad por ser física esencialmente es dinámica, kinestésica, en "hacia"; se da en ella un devenir radical que "dando de sí" todo lo envuelve; esto es la base para entender cualquier tipo de devenir animal, devenir materia, devenir naturaleza, para, en definitiva, devenir cuerpo, un devenir "estar aquí" propiamente humano. El "estar" presentándose propio de la actualidad se funda, como hemos visto, en la "actuidad". La actualidad deviene (actualización) en su doble consideración (cósmica y mundanal) junto a un devenir de "actuidad" (actuación) que la constituye; un devenir no es excluyente del otro, pero uno, el primero, se funda en el otro, en el segundo. El devenir de actualidad se funda en el de "actuidad"; se funda en lo físico mismo de la realidad como "estar". Y en este fundarse el "estar físico" está en actualidad corporal (estar actualmente siendo "aquí" cósmica y mundanalmente, esto es, cuerpo) en la realidad humana. En este "estar en actualidad" lo que deviene son cualidades de actualidad; ciertos modos físicos intensivos de ser actual. Por ejemplo, en el caso del hombre su fisonomía que es una cualidad de actualidad deviene en el horizonte de la actualidad de un hombre concreto, determinado en medio de las cosas reales (en este caso en medio de otros hombres); esto es, en medio 
del cosmos. El "estar" físico del hombre mismo es, a una, un "estar" que actúa en actualidad tanto en el "aquí" del cosmos como en la mera y simple realidad que es en el mundo. Y ese carácter talitativo del cuerpo humano como "estar aquí" se abre trascendentalmente, en "más", a la inespecificidad del mundo. El cuerpo humano es un "aquí" en apertura, en "más", y esto es lo que no vio el análisis existencial del $D a$ sein del primer Heidegger; de allí que el cuerpo sea anterior a cualquier tipo de organización de él mismo e incluso de cualquier tipo de subjetivación. Luego, la pregunta que nos surge de inmediato es la diferencia que hay en el devenir de la actualidad con respecto al de la "actuidad", porque, es obvio, que no es lo mismo en el caso humano. Un devenir afecta al carácter mismo físico de lo real (y del hombre) y el otro es un "traer a presencia" lo real mismo en cuanto real.

\section{¿En qué consiste este devenir de actualidad?:}

"Hay un devenir de lo real mismo según su actualidad, distinto de un devenir según actuidad. Lo cual no significa que en este devenir de actualidad formalmente considerado la cosa adquiera, pierda o modifique sus notas; la realidad no deviene como acto, pero sí deviene formalmente como actualidad. Ciertamente las cosas para ser actuales posiblemente tienen que actuar, esto es, adquirir, perder o modificar notas. Pero esta actuación no es aquello en que formalmente consiste la actualidad que con aquélla se ha logrado. El devenir de actualidad no es formalmente un devenir de actuidad" (Zubiri, 1984, 140-141).

Por tanto, las cosas reales pueden tener variadas actualidades, pero lo fundamental es que en ellas no se pierden, ni se modifican, ni se añaden notas (contenidos) a lo real (como sucede en la "actuidad") y esto es clarísimo en el caso humano. $Y$ esto es radicalmente importante para que entendamos la actualidad de modo esencial en un caso muy especial, como ámbito de mismidad numérica entre lo inteligido y el inteligir, esto es, como co-actualidad que sería la base para comprender después de milenios la sentencia de Parménides en su Fr.3 DK. Una cualidad de actualidad como la fisonomía de un hombre concreto que se presenta a los demás hombres no añade, ni quita, ni modifica a ese mismo hombre nada en lo que es esencialmente; simplemente lo presenta físicamente en un aquí cósmico abierto, por su cuerpo. Esto que piensa Zubiri radicalmente, durante toda su vida, no quiere decir que la actualidad sea algo accesorio al hombre, puesto que no lo dinamiza esencialmente, sino que el hombre cobra real y plena dimensión en la "expresión" de sí cuando se "ratifica" como tal, tanto en el cosmos como en el mundo; en ese carácter de ser mera "ratificación" (Zubiri, 1984, 234) ${ }^{18}$ es donde se da la actualidad; allí acontece toda la verdad mis- ma de lo real qua real. El carácter corporal noológico es expresión, intensidad afirmativa del hombre; el hombre se expresa corporalmente y es así como se "ratifica" como tal en el cosmos-mundo; se ratifica en ese carácter de ser mera verdad, mera actualidad de lo real en aprehensión sentiente. Entonces es obvio que: "... la actualidad... no añade ninguna nota física a lo real" $(1984,230)$. Si la actualidad no toca a las notas para nada en lo noto que son ¿qué es lo que hace con lo real? ¿Qué significa propiamente tal "estar actualmente"? Para poder entender esto de modo pleno, es necesario introducirnos, por ejemplo, en la actualidad de lo real en la intelección. Cuando el filósofo dice según la primera cita que colocamos al comienzo del escrito: "La actualidad de lo inteligido y de la intelección es numéricamente la misma, es idénticamente la misma" parece decir lo mismo que señaló en Sobre la esencia: “... en la aprehensión, la actualidad de lo aprehendido en cuanto aprehendido y la del aprehender en cuanto aprehensor son un acto y el mismo; si se quiere, no hay sino un solo acto, que es común a la cosa y a la mente" $(2008 a, 444)$. La cosa y la mente son lo que son, cosas reales acabadas en plenitud física, in actu exercito. Sin embargo, "están" en actualidad en el acto de aprehensión. Pero no podemos quedarnos en el momento de acto, sino que tenemos que entender la aprehensión en lo que formalmente es, "estar en actualidad". Si se confunde esto podríamos caer en la llamada "comunicación de sustancias" a la hora de entender en el acto de aprehensión, lo formalmente de ella, que no es ser acto, sino mero "estar en actualidad". Por esto, en este pasaje de Sobre la esencia, aunque el espíritu zubiriano sea el mismo, no se está diciendo formalmente lo mismo que en Inteligencia y realidad. De allí que se tenga que revisar la obra zubiriana con cuidado para ver cómo su concepción de la actualidad varía y en ello la del cuerpo. Pues está confundido e indiferenciado en el "estar" el carácter de acto con el de actual. Y esto será algo terminantemente diferenciado en el último Zubiri. De allí que tenemos que tratar de no confundirnos con el decir de sus textos en diferentes épocas de redacción que conllevan distintos niveles de maduración de su pensamiento. Eso sucede, por ejemplo, no solamente con el tema de la actualidad, sino también con la distinción entre "forma y modo de realidad", el concepto de sustantividad, de inteligencia, de respectividad, de verdad, de Dios, etc. Incluso en una misma obra (y al final de su vida) podemos encontrarnos con matices en su decir no del todo claro; por ejemplo, la diferencia entre "lo real y realidad" que yace en la Trilogía sobre la intelección no está del todo asumida y la confunde constantemente. Desde esta actualidad podremos entender realmente el devenir de la actualidad, un devenir que no quita ni añade ni modifica nada en 
el contenido de lo real, esto es, en su esencia simplemente ratifica lo que es, esto es, la da verdad.

Sabemos que, en modo propio, la actualidad es un "estar presente" de lo real en cuanto "estar" y no en cuanto presentarse: "La actualidad es un estar presente no en cuanto presente sino en cuanto estar" (Zubiri, 2008, 369). Esta idea, tantas veces expresada por Zubiri, debe ser matizada en su justo momento para dar con la actualidad y cómo ésta es la base para entender el "aquí" del cuerpo. Esto no quiere decir que el carácter de "presente" del "estar presente", en lo que consiste la actualidad, no tenga nada que ver con lo real. Lo que se quiere decir simplemente es que lo fundamental del carácter de actualidad de lo real no está en el carácter de presencia sino en el del "estar" físico que se ratifica; en lo físico mismo que se impone. Pero es obvio que lo real está en el mundo en tanto que "está presente" en él y en un "aquí" cósmico determinado, material diríamos para cualquier cosa real y el término corporal lo dejaremos para el hombre propiamente tal. Además, otra cosa importante de señalar es que este "estar, como hemos dicho," no añade ninguna nota física a lo real, sino que simplemente deja lo real en la realidad que "está siendo", ya en el cosmos ya en el mundo, lo deja en su mero "ratificarse", en su verdad. Esto es, la actualidad le añade a la cosa su mero carácter de ser. $Y$ lo haremos de manera detallada para explicar desde él la articulación tanto con la realidad y con el cuerpo. Lo que debemos tener claro en este momento es que la actualidad es el carácter de estar presente de algo real por el mero hecho de ser ya real. Y siempre, por esta razón, se está presente en el mundo. Y la actualidad de lo real en el mundo es el ser de eso real, de allí que realidad y ser se articulan desde la actualidad y su físico "estar" en un "aquí" cósmico y mundanal.

Con este breve estudio de la actualidad hemos podido ver cómo las notas constituyentes de la realidad de lo real están totalmente articuladas entre sí y son claves para dar con una concepción del cuerpo noológico como cumbre de toda una vida de reflexión. Por esto Zubiri en Inteligencia y logos incluso llega a identificar la formalidad con la actualidad y aquí, nosotros, no podemos no ver la importancia que adquiere al final de su vida el carácter físico. El carácter físico mismo de la alteridad de la formalidad se nos dice que es actualidad: "Lo aprehendido queda en la aprehensión según su formalidad: es lo que he llamado actualidad. Actualidad no es presencia, sino un estar en presencia. Es por tanto un momento físico de lo aprehendido" (1982, 12). A modo de resumen no olvidemos que actualidad es: “... el "estar» presente en cuanto estar: es lo real «estando» presente en y por sí mismo como real" (1982, 350-351). La mirada tanto sincró- nica como diacrónica de la realidad como formalidad nos arroja tres notas noológicas que han aparecido a lo largo del escrito: "prius", "más" y "hacia" que se articulan dinámicamente en la unidad "actualidad"19. $Y$ esto es fundamental dejarlo bien claro. En realidad, la actualidad como lo diacrónico mismo eleva a lo sincrónico de las notas, pues tal actualidad es la respectividad misma que constituye a cualquier sistema sustantivo que se analice. No solamente este constructo entre "prius", "más" y "hacia" se constituye desde su propia respectividad, sino que cualquier tipo de constructo lo hace así. Pero no es mera respectividad, sino respectividad en actualidad. Veámoslo.

El constructo de notas de cualquier sistema sustantivo que nos impresiona radicalmente en aprehensión, podemos llamar al constructo como "constructo actualizante" o "constructo en actualidad". Lo que sucede es que las notas mismas en ese "de" que se constituyen mutuamente entre sí se tornan respectividad $^{20}$. Las notas de cualquier sistema sustantivo pueden entenderse desde el carácter mismo de respectividad como constituyente de las notas o relatos. Ver a las notas como meros relatos en donde la unidad respectiva los constituye como tales, como un "prius" que acontece en ellos mismos, es entender el constructo de notas no ya desde las notas sincrónicas de la noología sino desde la unidad, pero de una unidad diacrónica en actualidad respectiva ${ }^{21}$. El carácter constructo de las notas respectivas entre sí realmente mienta la actualidad misma en un "aquí" corporizante. Y, por esto, Zubiri la llamó en su filosofía final respectividad en actualidad. Lo cual es completamente apropiado. Hay un texto en Reflexiones teológicas sobre la eucaristía que es realmente sorprendente porque señala lo que entiende finalmente por actualidad, después de muchos años, décadas, en que este concepto ha ido adquiriendo cada vez más importancia en su sistema filosófico. Es un texto único en donde se puede ver que el célebre estado constructo de las notas que constituye cualquier sistema es entendido desde la respectividad de dichas notas entre sí (en que cada nota luego se entiende como mera nota y por esto mismo ninguna nota de forma aislada tiene sustantividad alguna); respectividad que es entendida, y esto es lo más novedoso, como actualidad de las notas entre sí. Las notas se "presentan" las unas a las otras de un modo físico en que las notas acontecen entre sí y en esto se constituyen corporalmente en un primer momento somático. Veamos el texto: "La actualidad es siempre el carácter de una realidad respecto de otra, y este respecto es «presencia» de algo en algo. Este respecto presencial puede ser de diversa índole [y el texto continua con la distinción que Zubiri hace desde hace años de la actualidad 
en sus tres niveles distintos]" $(1997,408)$. Desde este texto no solamente la actualidad, ni tampoco la respectividad sino radicalmente la realidad entendida como sustantividad, como cuerpo, cobra un sentido más novedoso respecto de lo que se había dicho a lo largo de muchos años. Las mismas notas de cualquier sistema sustantivo ( $y$ en el caso del hombre es clarísimo), que están en unidad constructa, pueden ser entendidas de un modo diacrónico, en el sentido que esa notas se están presentando entre sí. Y esa co-presentación entre ellas es ese "de" del estado constructo (en definitiva, un modo de respectividad constituyente). Zubiri lo dice así en un texto de los últimos de su vida:

“... formalmente el estado constructo concierne al "de suyo» en cuanto tal, al momento de realidad, es decir, a la respectividad constituyente. El estado constructo consiste en que el contenido de cada nota, por ser «nota-de» es real, pero no es real sino respecto a la realidad del sistema... el "de suyo» concierne tan sólo al sistema mismo.... Sólo el sistema es sustantivo. La formalidad misma de realidad tiene, entonces, en respectividad transcendental, carácter de sistema" $(1979,34)$.

Con esta renovada interpretación del estado constructo de las notas del sistema vemos que el "de" mismo que funda al constructo de notas es visto desde la respectividad constituyente; en ese "de" en constructo estaría la base de cualquier materialidad y del cuerpo noológico. De allí que Zubiri habla del cuerpo no solamente como principio de actualidad sino que por serlo da de sí la solidaridad de los momentos y los organiza (2006, 108-111). Y ahora Zubiri da un paso más. Hasta al final de su vida sigue precisando conceptualmente lo más propio de su pensamiento; el pensador, cual escultor, siguió sacando esquirlas a la realidad para que ésta diera lo mejor de sí.

La respectividad constituyente de todo lo real en cuanto sistema constructo de notas es visto desde la actualidad misma; actualidad que es un caso de respectividad. Entonces tenemos que ahora se habla de la realidad en respectividad en términos de actualidad, del carácter de "estar presente" de la realidad, de cualquier realidad, incluso de las notas de un sistema, entre otras realidades (o notas). La realidad se afirma radicalmente en tanto respectividad, pero, si la entendemos como actualidad ${ }^{22}$, esta respectividad cobra el sentido fuerte de mostrarnos que esa respectividad que funda constituyendo los relatos es un carácter constituyente en la medida en que esos relatos se "están presentando" entre sí en un "aquí abierto", en el cuerpo. Y esto es realmente el devenir de actualidad de la realidad; devenir que no mienta el carácter de devenir de actuidad de ella.
Todas las cosas reales por ser reales están siendo, en su propia respectividad, actuales las unas a las otras, se presentan las unas a las otras en tanto que actuales; en esto consiste su radical carácter de verdad. Por esto podemos ver que tenemos una profundización del pensamiento noológico zubiriano. Primeramente es la realidad, la realidad como "de suyo"; segundo, por ser "de suyo" es un "prius más" que un determinado carácter de realidad, es el carácter de transcendentalidad o, si se quiere, de apertura respectiva (o simplemente de respectividad); tercero, por ser respectiva, la realidad se presenta como realidad; es el carácter de actualidad (por ejemplo, pensemos en las notas de un constructo en la cosa misma) y, finalmente, hay un tipo de respectividad en actualidad en que lo real está presente dinámicamente, pero en el mundo:

\begin{abstract}
"Por ser formalidad abierta la cosa real siendo real es más que sí misma. Por tanto, está presente en el mundo, es la realidad abierta en que estructuralmente consiste. No se trata de una mera presencia, porque presencia es la manifestación externa de lo que temática y formalmente llamo actualidad, a diferencia de «actuidad»" (Zubiri, 1979, 41).
\end{abstract}

Este texto es muy interesante, porque podemos ver claramente tres cosas. Una, que Zubiri entiende actualidad siempre en contraste con la actuidad (estos términos antes estaban en su pensamiento indiferenciados en el término "actualidad"). La segunda que actualidad mienta simplemente "presencia" (pero en cuanto "estar" presente). Es un modo de respectividad en que lo real mismo se presenta en su propio carácter de realidad. El mejor ejemplo para esto son las notas de un sistema constructo. Esa unidad de respectividad constituyente de las notas entre sí sería el modo de presencia, su carácter de actualidad, en el sentido más fuerte. $Y$, finalmente, la tercera cosa que podemos ver es que hay un tipo de actualidad, un tipo distinto de respectividad en actualidad en que lo real está presente no para sí mismo, por decirlo de alguna manera, no en cuanto a su propio carácter realidad, sino que es una actualidad en que lo real está presente en el cosmos-mundo (digamos de inmediato que esto es el ser como la actualidad mundanal).

Por tanto, el carácter de respectividad constituyente de todo lo real por ser real es entendido en términos de actualidad como el carácter que funda los relatos, en cuanto estos relatos se presentan entre ellos mismos en un aquí mundanal. $Y$ esto es lo novedoso de este último Zubiri y su noología corporal. $Y$ aquí radica, en sentido fuerte, lo que sea el devenir de actualidad:

"La actualidad es un momento que admite un devenir. Ante todo, el devenir de actualidad no es el devenir de propiedad, pero es, sin embargo, un fí- 
sico devenir: se llega a tener actualidad o a dejar de tenerla sin el menor cambio de propiedades en quien es actual: el devenir de actualidad no es un devenir de actuidad. Este devenir es un momento de la actualidad misma, no sólo por parte de aquello en que algo se hace actual, sino ante todo por parte de aquello mismo que se hace actual: es la realidad misma la que deviene en actualidad" (Zubiri, 1997, 410).

Esto es la actualidad de manera definitiva y un tipo de actualidad es la actualidad mundanal o actualidad en respectividad transcendental pero ésta actualidad también es cósmica talitativa, esto es, en su conjunto es el carácter en que lo real está presente "aquí" en el cosmos-mundo; es decir, el ser, pero un ser en toda su materialidad y en el hombre, en su cuerpo. La sentencia "la realidad es actual" significa como ya sabemos que es dinámica, que deviene, que "está presente" como real ante todo otro carácter real; $y$, en esto, se constituye como tal en sistema sustantivo corporizado, ya pensado en algo inteligido, ya pensado en cualquier cosa real, ya pensado en la totalidad de las cosas. Todas ellas están en respectividad de actualidad 0 , si se quiere, en respectividad de presencia que las constituye formalmente. $Y$ un modo de presentarse, de devenir actual de lo real es devenir en el carácter cósmico-mundanal de la propia realidad en su imposición. La realidad queda a la luz de su ser, queda iluminada por la luz de su propio ser. Zubiri nos explica el ser de este modo en Respectividad de lo real:

“... [el ser] no es presencia, sino estar presentándose en cuanto estar. La apertura de la realidad es ahora respectividad como actualidad. La respectividad constituyente es el fundamento de toda actualidad. Ahora bien, entre todas las actualidades que lo real puede tener hay una que es primaria y fundamental, y que, por tanto, se suprema actualidad: es la actualidad de la cosa real en el mundo, en ese mundo que ella misma ha determinado dentro de sí misma por respectividad constituyente. $Y$ la actualidad de lo real en el mundo es justo el ser" (Zubiri, 1979, 42).

Por tanto, a través de estos textos finales de la obra zubiriana ${ }^{23}$ tenemos que la realidad "da de sí" su ser en la medida en que ella es radicalmente actual; esto es, se está presentando y se está presentando por el carácter de mero "estar" o mero ser real de ella misma en un "aquí". Y se está presentando por ser real en el mundo por ella abierto, un mundo cósmicamente "aquí" abierto en trascendencia dinámica; esto es, en una corporización que todo dinamiza. En el caso del hombre es un cuerpo que se subjetiva, social e históricamente.

\section{CONCLUSIÓN}

Finalmente, podemos señalar que en la última filosofía de Xavier Zubiri, su noología, nos permite hacernos una idea en lo que estaba pensando el filósofo y en ello nos damos cuenta de que el concepto de actualidad tiene una riqueza tal que no solamente explica lo que es la realidad como formalidad de actualidad sino que es el concepto clave que articula a la realidad con el ser, porque actualidad implica un "estar siendo", esto es, estar en presencia, pero en presencia física cósmica y mundanalmente. Y allí radica la radicalidad y riqueza de la noología zubiriana que al describir el acto de aprehensión humana como mera actualización de lo real en tanto que real está integrando toda su filosofía desde el carácter físico del estar en su presentación cósmica-mundanal.

Y esta articulación integradora de realidad y ser, esto es, de estar y ser, en tanto que "estar" presente nos permite, por fin, ver lo buscado por años por el filósofo español, una concepción de la materialidad, de la naturaleza y, en definitiva, del cuerpo de un modo en que la actualidad nos permite ver el "estar aquí" mismo de lo real en el cosmos y en ello abierto trascendentalmente en el mundo. Y este "estar aquí" en el caso del hombre es su cuerpo, lo más propio de él. En esto radica realmente el carácter "de suyo" del hombre: "El «de suyo» es el cuerpo mismo, el cuerpo en el Cuerpo mismo que nos arrebata, que nos mueve, que nos exhorta, que nos lanza, etc. con excedencia, desmesura, abundancia en libertad a construir, crear, organizar" (Espinoza, 2007, 109-110).

El cuerpo es la actualidad misma del hombre, es su estar siendo en el cosmos con toda su materialidad individual, social e histórica. Es un cuerpo de suyo propio, entre otros cuerpos, ya del modo filético, ya del modo social y es, además, un cuerpo que se entrega de generación en generación como ciertas capacidades de actualidad, es decir, modos de ser físicamente en el cosmos y de estar abiertos al mundo, es la historia entendida de un modo corporal. Y allí, en definitiva, estaría el carácter teologal corporal que integra todas estas otras dimensiones humanas como un cierta religación en comunidad de unos con otros en vistas a algo que los supera y les da un sentido, un cierto camino por donde deben caminar en conjunto, con su propia individualidad, entre todos y en esas dotes actuales que se han entregado. 
1 Dr. Ricardo Espinoza Lolas es doctor en Filosofía por la Universidad Autónoma de Madrid y Catedrático de Historia de la Filosofía Contemporánea de la Pontificia Universidad Católica de Valparaíso. Es Director del Postgrado de Filosofía de la misma universidad y miembro y profesor de la Fundación Xavier Zubiri de Madrid. Autor de más de 26 artículos en torno a Zubiri, también ha escrito dos libros: Realidad y tiempo en Zubiri (Comares, 2006) y Zubiri ante Heidegger (Herder, 2008).

2 Dra. Paula Ascorra Costa es doctora en psicóloga por la Universidad de Chile y en la actualidad Jefa de Docencia de la Escuela de Psicología de la Pontificia Universidad Católica de Valparaíso. E-mail: pascorra@ucv.cl

3 Dr. Esteban Vargas Abarzúa es doctor en filosofía por la Pontificia Universidad Católica de Chile y en la actualidad es Profesor Asociado del Instituto de Ciencias Religiosas de la Pontificia Universidad Católica de Valparaíso. E-mail: esteban.vargas@ucv.cl

4 El término de actualidad tan importante en el pensamiento final de Zubiri puede ser rastreado en el pensamiento de $\mathrm{Hei}$ degger. En el año 1930, Heidegger dictó su gran conferencia De la esencia de la verdad (publicada luego en 1943); que inaugura el cambio de su pensamiento, el giro (Kehre), como el mismo Heidegger lo llama, al interior de su reflexión y que nos lleva del hombre al ser mismo (ese ser que no pudo salir a la luz en Sein und Zeit) por medio de la verdad. La verdad entendida en esta nueva posición como Lichtung (idea que está presente en todo el pensamiento heideggeriano posterior a 1927) trae la idea de que son las cosas las que nos permiten juzgar sobre ellas. Nuestros juicios serán "verdaderos" porque de antemano la cosa "verdadea". La cosa porque se "hace presenta" es porque puede ser "re-presentada" en el juicio. Esto es, la verdad como conformidad o adecuación reposa en algo anterior que la constituye; y esto es propio de la cosa en cuanto a su carácter de presentarse. Véase, por ejemplo (Heidegger, 1996, 114-116). Aquí ya está incoada la idea zubiriana de la actualidad. En el término "stellen" con todas sus variantes ya podemos encontrar indicios de la actualidad como "estar presente en cuanto estar". Que sirva lo dicho como nota introductoria para esta importante categoría zubiriana.
5 Texto publicado íntegramente en la segunda edición de Espacio, Tiempo, Materia (Zubiri, 2006) y que editó uno de los autores de este escrito, Dr. Esteban vargas.

6 Véase (Espinoza, 2012). En este libro se trabaja en detalle el problema de la articulación realidad y ser; articulación clave para entender la concepción de cuerpo en el último Zubiri.

7 Véase (Zubiri, 2008, 329-330).

8 "Para Zubiri la Fenomenología dio un paso muy importante en el estudio, sin teorizar, del hecho mismo dado en la aprehensión, pero se quedó, en el fondo, muy pobre en su descripción porque radicalmente nunca fue una descripción "física» del hecho mismo de la aprehensión... Pues, lo que sucedía con la Fenomenología era que se escondía en ella un rasgo fundamental de lo que Zubiri llama Inteligencia concipiente: la dualidad entre sentir e inteligir" (Espinoza, 2006a, 342-343).

9 "La tesis de Zubiri, explicada para fenomenólogos, consiste en decir que si tomamos cualesquiera de esos "contenidos presentantes» nos encontramos con algo que no es puro contenido. Es justamente lo que Zubiri llama «formalidad de realidad». Se trata de que los contenidos, en la misma impresión, quedan en ella como radicalmente independientes de la misma" (González, 2008, 121).

10 Para entender en detalle lo constructo o el logos nominal constructo zubiriano, véase (Espinoza, 2000/2001). Este logos constructo afirma la realidad de modo constructo, esto es, de un modo articulado, donde no se da el sujeto con el predicado, sino que la realidad misma se impone y por ende se afirma como una constelación de notas. Y de aquí el carácter sustantivo de la realidad y nunca sustancial para Zubiri.

11 Respecto al tema del signar propio de la realidad, véase (Espinoza, 2010)

12 Aquí radica la concepción de la Naturaleza que en su propia inmanencia se vuelve creadora, dadora de sí. Esto lo hemos estudiado en otro artículo de este Fondecyt (Ascorra, Espinoza y Vargas, 2012a)

13 En torno al problema del ser como "luz" en la filosofía de Heidegger, véase (Espinoza, 2011).
14 "Desde el alba del pensar occidental europeo hasta hoy, ser quiere decir lo mismo que asistir o estar presente [Anwesenheit]" (Heidegger, 2000, 10). "Sein besagt seit der frühe des abendländisch-europäischen Denkens bis heute dasselbe wie Anwesen" (Heidegger, 1969, 2).

15 Para el tema de la génesis del problema del cuerpo en Zubiri, véase (Espinoza y Ascorra, 2011).

16 "El concepto de actualidad es el que está anclado en el "estar» y es el que nos vincula con el "presentarse» de ese "estar» y no en cuanto a su modo de presentarse podemos de inmediato darnos cuenta de cómo se comprende el problema de la ligazón entre realidad y ser desde el "estar» de la actualidad. Esto es algo que debe tenerse muy en cuenta porque aquí se indica la dominancia del «estar» en respectividad con la "presencia», esto es, la dominancia respectiva entre la realidad y el ser. Es el "estar» el que otorga y constituye la presencia como tal" (Espinoza, 2006, 20-21).

17 "La realidad «es», está siendo en el mundo, y en eso es actual en el mundo. La realidad por ser, es actual en el mundo y esta actualidad mundanal, su ser, recubre la propia realidad como «ente»" (Espinoza, 2006, 332).

18 Es obvio que la interpretación zubiriana del ser como "actualidad mundanal" de lo real o, si se quiere, el ser es el estar presente de lo real en el mundo, es una concepción del ser a partir de Sein und Zeit. Es Heidegger el que define al Dasein en términos de "das Inder-Welt-sein" (expresión que Gaos ha traducido por "ser en el mundo", pero que Rivera traduce mejor siguiendo a Marías y al propio Zubiri como "estar en el mundo"). Para tener presente lo que indica esta expresión heideggeriana sumamente recurrente en su famoso libro se puede ver, "Capítulo Segundo. El estar-en-el-mundo en general como constitución fundamental del Dasein", en (Heidegger, 1997, 79-89). Lo que para Heidegger mienta una estructura del hombre en respectividad con el ser, para Zubiri es la expresión misma de cualquier cosa real que esté siendo en el mundo.

19 “... en el caso de la realidad humana, ésta no se puede entender acabadamente sin su dimensión del yo, de su 
siendo como yo; la actualidad mundanal de la realidad humana es el yo" (Espinoza, 2006, 339). Y es interesante remarcar que el yo como el ser de la realidad humana se entiende desde el tiempo como historia: "El tiempo de la historia es el tiempo de la "altura de los tiempos» y es el tiempo del ser de la realidad humana, esto es, el yo en su unidad total" (Espinoza, 2007, 290).

20 Para entender la fundamentación del filosofar de Zubiri con Nietzsche, véase (Ascorra y Espinoza, 2012).

21 Antonio Pintor señala: “¿Qué significa tal ratificación? No debe entenderse este término como si se tratase de otro acto distinto que, suponiendo ya la actualidad intelectiva, se pronunciase de modo explícito sobre la realidad allí actualizada; esto sería una especie de larvada afirmación que, como sucedió a veces en la doctrina tradicional de la simple aprehensión, desplazaría la verdad real al terreno del juicio e introduciría de este modo una distancia dual entre inteligencia y realidad, que... no cabe en la aprehensión primordial. Mucho menos aún cabe entender tal ratificación como una explicita toma de conciencia respecto a la realidad actualizada... Nada de esto significa la «ratificación" propia de la verdad real; ese término sólo designa el estar presente de la realidad en la intelección, donde el acento debe recaer en el "estar» como momento físico y no debe desviarse hacia una primacía de la presentidad; queda entendido, pues, que el término «ratificación» es aproximativo y un tanto mecánico" (1994, 108-109).

22 "... desde dentro de la aprehensión, y sin salir de ella, precisamente por su carácter espacioso y tempóreo y por los fenómenos del "prius», "más« y del «hacia», podamos hablar de la realidad como más que puntual, como teniendo una realidad que de suyo trasciende o puede trascender el puro momento" (Gracia, 2004, 99)

23 Vemos que la actualidad debes ser entendida radicalmente desde el carácter de respectividad. La actualidad es un modo de respectividad. $Y$ esto no podemos olvidarlo. Hay muchos modos de respectividad y uno de ellos es la actualidad intelectiva. Este tipo de actualidad funciona desde el mismo supuesto que cualquier otro tipo de actualidad, desde la respectividad. Aquí los relatos que se constituyen es a la vez lo inteligido mismo y el inteligir. Pedro Cerezo lo señala muy bien: "La actualización se opone... a la mera re-presentación (Vor-stellung). Es la presencia efectiva de algo en su manifestación desde sí y por sí en y para la inteligencia, poniendo a ésta en su acto propio de aprehender. No es, pues, una relación predicamental entre inteligencia y algo real, sino pura "respectividad»" (Cerezo, 1996, 62)

24 Diego Gracia explica esto de forma muy clara: “... la cosa real en tanto que «de suyo" es un "constructo" de notas. Esto significa que las notas son «notas-de» las demás de la cosa real. Vista desde las notas, la realidad es un «constructo»; el de suyo es, pues, un "constructo" de notas. Si se adopta la perspectiva contraria y se ven las notas desde la realidad, entonces el de suyo no aparece como constructo sino como extructo o "estructura». En ambos casos las notas se nos actualizan como "respectivas». Cada cosa tienen respectividad interna hacia sí misma, es respectividad a su propia realidad: es lo que Zubiri denomina "respectividad constitutiva»" $(1986,183)$

25 “... é necesario indicare il fatto che l'attualitá non é né relazione, né correlazione. Nell'apprensione'io vedo una parete' non si stabilisce, innanzitutto, una relazione tra la visione e la parete; al contrario, la relazione é qualcosa che si stabilisce dopo l'aver visto la parete. La visione é, dunque, qualcosa di antecedente la relazione: é un attualitá nella quale sto vedendo una parete. Piú che una relazione, allora, l'attualit'a 'e una rispettivitá” (Ponzio, 2007, 104).

26 Los textos de la actualidad que hemos trabajado principalmente son pensados y escritos en los últimos años de vida de nuestro pensador (murió en 1983). Espacio. Tiempo. Materia en lo referente a los textos de la actualidad que hemos trabajado son de a mediados de los años 70. Respectividad de lo real es de 1979. Reflexiones sobre la eucaristía es de 1980. Inteligencia sentiente (el primer volumen) es 1980 e Inteligencia y logos es de 1982.

\section{BIBLIOGRAFÍA}

Ascorra, P. y Espinoza, R. (2012): "Heidegger y Zubiri... y el problema de Dios", VERITAS. Revista de Filosofía y Teología, Septiembre [En prensa]

Ascorra, P., Espinoza, R. y Vargas, E. (2012a): "Nietzsche y la concepción de la naturaleza como cuerpo", Revista ALPHA, 34.

Cerezo, P. (1996): “El hombre, animal de realidades", en La filosofía de Zubiri en el contexto de la crisis europea, Santiago de Compostela, Universidad Santiago Compostela.

Espinoza, R. (2000/2001): “El logos nominal constructo en el pensamiento de Zubiri", The Xavier Zubiri Review, 3:29-57.

Espinoza, R. (2006): Realidad y tiempo en Zubiri, Granada, Comares.

Espinoza, R. (2006a): “Zubiri y Husserl. Una crítica desde el carácter físico a la intencionalidad", Cuadernos Salmantinos de Filosofía, 33: 341-368.

Espinoza, R. (2007): “Deleuze y Zubiri.en torno a una lógica de la impresión", CONTRASTES. Revista Internacional de Filosofía, 12: 93-112.

Espinoza, R. (2007a): "En torno al problema del tiempo de la realidad humana", PENSAMIENTO. Revista de investigación e información filosófica, 63(236): 267 302
Espinoza, R. (2010): “En torno al problema del signo en el último Heidegger a la luz del pensamiento de Xavier Zubiri", Cuadernos salmantinos de filosofía, 37:201223.

Espinoza, R. (2011): "Zubiri y Sein und Zeit", en Guía comares de Zubiri. Granada, Comares, 194-209.

Espinoza, R. (2012): Realidad y ser en Zubiri, Granada, Comares [En prensa].

Espinoza, R. y Ascorra, P. (2011a): “Cuerpo y alma en Zubiri.Un problema filosóficoteológico", Pensamiento, 67(254):10611075. 
González, A. (2008): "Las cosas”, en Zubiri ante Heidegger, Barcelona, Herder.

Gracia, D. (1986): Voluntad de verdad. Para leer a Zubiri, Barcelona, Labor.

Gracia, D. (2004): "La antropología de Zubiri", en Balance y perspectivas de la filosofía de X. Zubiri, Granada, Comares.

Heidegger, M. (1969): Zur Sachen des Denkens, Tübingen, Niemeyer Verlag.

Heidegger, M. (1996): Qué es metafísica y otros ensayos, Buenos Aires, Fausto.

Heidegger, M. (1997): Ser y tiempo, Santiago de Chile, Universitaria.

Heidegger, M. (2000): Tiempo y ser, Madrid, Tecnos.
Pintor-Ramos, A. (1994): Realidad y verdad. Las bases de la filosofía de Zubiri, Salamanca, Publicaciones Universidad Pontificia de Salamanca.

Ponzio, P. (2007): Veritá e attualitá. La filosofia dell'intelligenza in Xavier Zubiri, Edizioni di Pagina.

Zubiri, X. (1979): "Respectividad de lo real", en Realitas III-IV , Madrid, Sociedad de Estudios y Publicaciones, 13-43.

Zubiri, X. (1982): Inteligencia y logos, Madrid, Alianza.

Zubiri, X. (1982): Inteligencia y razón, Madrid, Alianza.

Zubiri, X. (1984): Inteligencia sentiente/ Inteligencia y realidad, Madrd, Alianza.
Zubiri, X. (1997): El problema teologal del hombre: Cristianismo, Madrid, Alianza.

Zubiri, X. (1998): El hombre y Dios, Madrid, Alianza.

Zubiri, X. (2004): Naturaleza, Historia, Dios, Madrid, Alianza.

Zubiri, X. (2006): Escritos Menores (19531983), Madrid, Alianza.

Zubiri, X. (2008): Espacio, Tiempo, Materia (Nueva Edición), Madrid, Alianza.

Zubiri, X. (2008a): Sobre la esencia (Nueva Edición), Madrid, Alianza. 